\title{
The Role of Real Estate Development in Solving the Housing Crisis in Algeria, Case Study the Greater Annaba
}

\author{
Sid Ahmed Soufiane ${ }^{1}$ \\ ${ }^{1}$ Faculty earth science, geography and planning, Constantine 1 University, Algeria \\ Correspondence: Sid Ahmed Soufiane, Department of Urban Planning, Badji Mokhtar University, Annaba, \\ 23220, Algeria. E-mail:universid.dz@gmail.com/ufc23dz@googlemail.com
}

Received: March 2, 2012 Accepted: March 20, 2012 Online Published: May 22, 2012

doi:10.5539/jgg.v4n2p102 URL: http://dx.doi.org/10.5539/jgg.v4n2p102

\begin{abstract}
The housing crisis is not only founded in underdeveloped countries, it has also different aspects of concern of the governments of industrialized countries. Governments, local governments and the private sector are expected to implement different strategies to solve this problem.

Our major concern was to focus on the experience of real estate development; however, we have attempted to extend our investigation to capture the degree of satisfaction of needs of residents' in relation to the new housing policy (five-year program 2005-2009), to solve the housing crisis that continues to grow it.

Real estate development is one of the aspects of housing production as well as the improvement of flat policies. If construction of housing is relatively old, the birth of binding activity of real estate development is rather recent (Law No. 86-07 of 4 March 1986 on property development).

This analysis will then identify the causes of the problem and propose recommendations based on a collaboration between various population sample who are involved in the operation of housing production (developers, prime contractor, prime contractor, ...) in order to reduce the shortage in housing and provide a good quality that meets the people needs according to their lifestyle and vocation of space.
\end{abstract}

Keywords: the housing crises, new formula, real estate development, five-year program, inter Annaba

\section{Introduction}

Population growth and urban migration in Algeria have characterized by a demand without growing housing. Economic growth and the underlying constraints, the sociological trends and social changes were occurring elements to the housing crisisin Algeria.

In addition, the housing deficit, with the slower growth resulting from the fall of oil revenues, in 1986 (Sid, 1986), which has become the sign of a relative failure of government despite the release of individual initiative in the 1980s (Benamrane, 1980). Until 1980, the state is practically the only developer of housing. Financially, it will have spent 10 billion DA housing between 1962 and 1979, and over 71 billion dinars from 1980 to 1989 (Semmoud, 1998).

\section{Key Factor to the Housing Crisis}

We can summarize the main factors that are produced this crisis:

- The historical factor which highlights the legacy of colonialism on the one hand and in other hand the support of the housing issue in Algeria after independence.

- The social factor, which shows certainly a growth less extensive, but a very young population and therefore relating on house demanding (Avril \& Roth, 1997).

- The economic factor, which determines the capacity of carrying out production operations and it stills in total mismatch with the changing demand.

Certainly, the succession of flows of rural-urban migration due to the implementation of industrial bases in the major cities and under the double effects of increasing important to the population after independence, are among the main factors of the housing crisis. Moreover, it has a low number of completed housing results in the inability of the state to meet these demands and endless the depletion of the fund public. 


\section{The New Housing Policy after 1990}

Algeria in its new housing policy, is seeking to withdraw from certain missions; it wants to operate the construction market by limiting the role of regulation and control.

The housing was listed for the first time in the state as well as it wasthe first priority of it; new objectives reflect the development of a real strategy of development and production of social housing. It is a strategy that the state decides to include in order to achieve a continuity of housing policy, the government set up special resources, new ways are the "legislative, institutional and resource" means that financial, human and material are relatively large for being made to implement this dynamic field.

Therefore, after a transitional period from 1988 to 1990, the economic crisis caused mutations of a socialist regime to a democratic state with integration systemof market economy and new political and economic choices. Creating a special fund to finance social housing, encourage the rental market, as there are 400,000 homes (Report CNES, 1995), all unoccupied type confused, and agree that appropriate legislation protects both the housing sector in concerning with the agreement of long-term loans.

Indeed, this leads to the integration of different modes of production of housing such as Public housing, housing support participatory promotional housing, housing lease, the cooperative.

According to occupancy house, the housing shortage is around 1.2 millionunits. In addition, 120,000 new households are generated annually. To address these important issues, the housing needs are established through a participatory process that should be more directly implemented with respect to different income groups.

To induce a new dynamic using the state manifests itself in differentways; several forms of direct and indirect subsidies are granted to both developers and recipients.

\section{Genesis and Definition of Property Development in Algeria}

Since 1986, the financing and production of promotional call for home new formulas, new resources are put in place by the powers of Public given the scale of needs, complexity of parameters at savings, and the cost of construction. It was envisaged medium-term program to make housing promotional; this initiative has had the advantage of substantially increasing the number of homes on the market.

\subsection{Definition According to the Legislative Framework}

"The set of actions contributing to the achievement or renovation of real estate properties for sale, rental or meeting needs prospers. The estate assets concerned for residential premises or premises for an occupation, trade or business" according to Article 02 of Legislative Decree No. 93-03 of March 1, 1993, on the activity of property development. Indeed, one finding two types of property development:

\subsubsection{Promotion of Private Housing}

Private real estate development aimed to provide "a new dynamic" to the construction industry and relieving the public sector in difficulty, and create housing for the category of "high standing".

\subsubsection{Real Estate Development Public}

The main operators of public real estate development are:

- The EPLF: Enterprise Promotion of Family Housing are responsible for achieving improved luxury homes, these homes are designed to meet the needs of applicants for home ownership; this accession takes place either in the form of a contract to sell a completed home or in a reservation contract with a housing to be built in accordance with a plan chosen.

- The DOPM: Development Office and Property Management, from 1985, statutes of these bodies had been recast, their new goals were to provide local instruments for the promotion and management estate. They have become local institutions of economic, as well as they were with new ways that enable them to ensure their new mission.

\section{New Formula Structuring the New Strategy of Solving the Housing Crisis}

The main components of this strategy (five year program from 2005 to 2009) are:

\subsection{The Formula for Public Rental Housing (LSL)}

Social housing is considered fully funded by any housing funds: the public treasury or the state budget. Social housing for people living under conditions is very precarious and whose resources do not pay rent even less high to apply to the acquisition of housing. 
Table 1. The launch and delivery of housing during the period 2005-2009

\begin{tabular}{llllllllllllll}
\hline Year & LPL & & \multicolumn{3}{c}{ LSP } & \multicolumn{3}{c}{ Rent-sale } & \multicolumn{2}{c}{ Promotionnel } & \multicolumn{2}{c}{ self-construction } & \multicolumn{2}{c}{ Rural } \\
& Launch & Delivery & launch & Delivery & launch & Delivery & launch & Delivery & launch & Delivery & launch & Delivery \\
\hline 2004 & 72850 & 24668 & 25028 & 17285 & 49115 & 5885 & 38068 & 9292 & - & 35293 & 49607 & 24045 \\
2005 & 112053 & 25834 & 84184 & 15787 & 0 & 12350 & 3837 & 8027 & - & 27574 & 132765 & 42907 \\
2006 & 38689 & 43527 & 57538 & 23769 & 2696 & 7128 & 5558 & 8435 & 39160 & 18630 & 137017 & 76287 \\
2007 & 35145 & 44079 & 32288 & 19325 & 8941 & 8491 & 5588 & 5028 & 28647 & 14671 & 78852 & 88336 \\
2008 & 67053 & 57657 & 43736 & 37123 & 837 & 1827 & 7956 & 4070 & 26637 & 15176 & 79595 & 104968 \\
2009 & 130240 & 55550 & 23607 & 37924 & 0 & 9043 & 10808 & 5644 & 33739 & 18142 & 70853 & 91492 \\
Total & 456030 & 251315 & 266381 & 151213 & 61589 & 44724 & 71815 & 40496 & 983998 & 129486 & 548689 & 428035 \\
\hline
\end{tabular}

Source: Ministry of Housing and Urban Planning, 2010

\subsection{The Form of Participatory Social Housing or Help (LSP-LPA)}

This housing achieved through assistance of the state was known asassisted home property pursuant to Executive Order 94-308 of October 1994 which defines the rules of procedure of the "NHF" (the National Housing Fund) on financial support for households.

\subsection{The Promotional Formula of Housing}

The promotional housing addresses the social category called "average", it consists mainly of low-income workers and their access to home ownership can be availed only to the value of a financial package to medium and long term

\subsection{The Formula of Accommodation Sales (Rent-sale)}

This type of housing is a new segment of housing supply that establishes and describes the favor of Executive No: 01-105 of 23 April 2001 laying down the conditions and terms of the acquisition through rent-purchase housing that made public funds (see Figure 1).
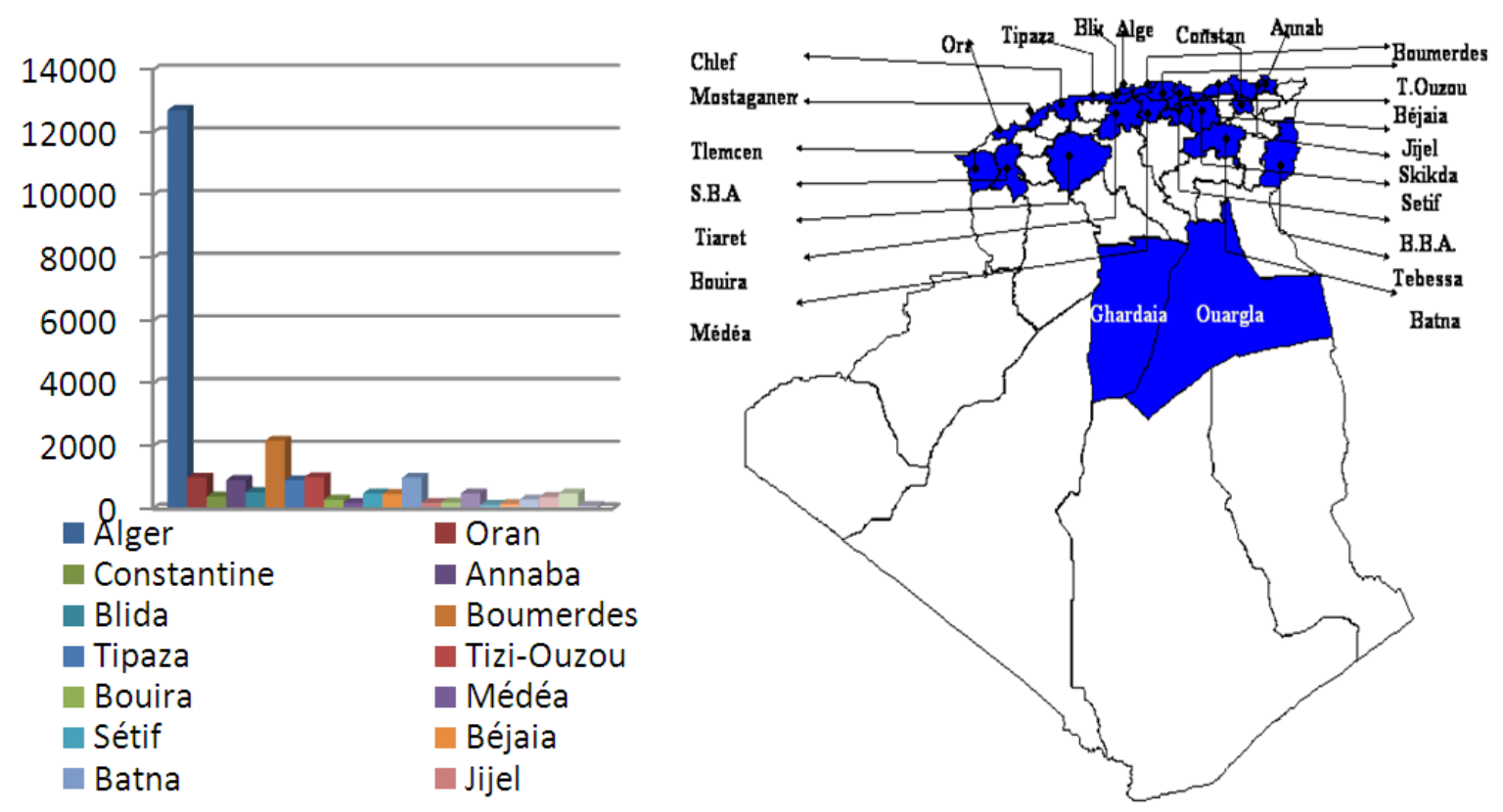

Figure 1. Distribution of housing lease in Algeria (Programme, 2002)

Source: official website (www.aadl.com.dz/generale2009.htm) 


\subsection{The Formula Rural Housing}

Rural housing fits into the framework of rural development policy, its objective is the promotion of rural areas and the establishment of local populations. It is founded to encourage households to achieve self-build and decent housing in their rural environment.

\section{The New Housing Policy in the Greater Annabi}

\subsection{A Privileged Location}

The geographical position of Annaba in the national and regional levels indicates the role that could play in the future. Its level of equipment, its economic foundations and communications as well as the characters of his physical and natural environment are all factors directly affect the urban system, which is based by these satellite towns El Bouni, Sidi Amar and El Hajar.

Annaba city has a population of nearly 600,000 inhabitants. $90 \%$ are concentrated in the four common Annaba El Hajar, El Bouni, and Sidi Amar who constitute the vast agglomeration Annabi (depending on the inter PDAU), i.e. almost $18 \%$ of the territory of the city, which is characterized by a concentration of $90 \%$ of its population of $18 \%$ of its territory.

The concentration level will reach nearly $96 \%$ for inter-and near 100\%at the city of Annaba (Sid Ahmed soufiane, 2010). Like all Algeriancity, Annabahas benefited from several programs housing. Nevertheless, the deficit remarkable land of plate was induced by the scarcity of land reserves in a constraint to the projection of the program listed in the five-year program (2005-2009) which includes 24993 (16630 LGTS 8363 supplementary program) of all housing formulas combined. It is composed: A complementary program was launched during the period 2006 and 2008; the registration of social rental housing is 5500 for the resolution of make shift housing, social housing in 2379 and 484 participatory rural housing (see Table 2).

Table 2. The launching of thefive-year programAnnaba city (2005-2009)

\begin{tabular}{lcccc}
\hline Type of housing & Lancement & achèvement & En cours de réalisation & Non lancer \\
\hline Socialrentedhousing & 4000 & 3330 & 670 & - \\
Participatorysocialhousing & 5157 & 1267 & 3890 & - \\
rural Housing & 4843 & 2540 & 1547 & 756 \\
Specialhousing & 2630 & 484 & 2146 & - \\
\hline
\end{tabular}

Source: DLEP of Annaba city and author's survey, 2011

Among 9500 social rented housing, $81 \%$ projected in the Greater Annaba. The investigation has gathered throughout our Air Force, to see that the number of applicants for this formula is 17,709 applications between 2005 and 2011. The gap between supply and demand is 8209 units.

\subsection{Analysis and Discussions}

The analysis of the distribution of apartment (housing) by occupational group of household head, shows that the allocation of housing built under public programs, which has benefited mainly for middle and senior management, and professional, employers.

The contribution of participatory social housing is housing for all 9866 of Annaba city and the Greater Annabi to receive $92 \%$ of the total, against the number of applicants for this formula in our Air Force is 35,459 requests, the housing deficit is 25,593 , while the program saves, a completion rate is $58.50 \%$ and 41.50 under construction.

Rental housing programs sales were split into two tranches: the first scheduled game in 2001, was involved in 2576 residential units on the town of Annabaand Sidi Amar (see Figure 2), and 924 units in the second installment 2002. 


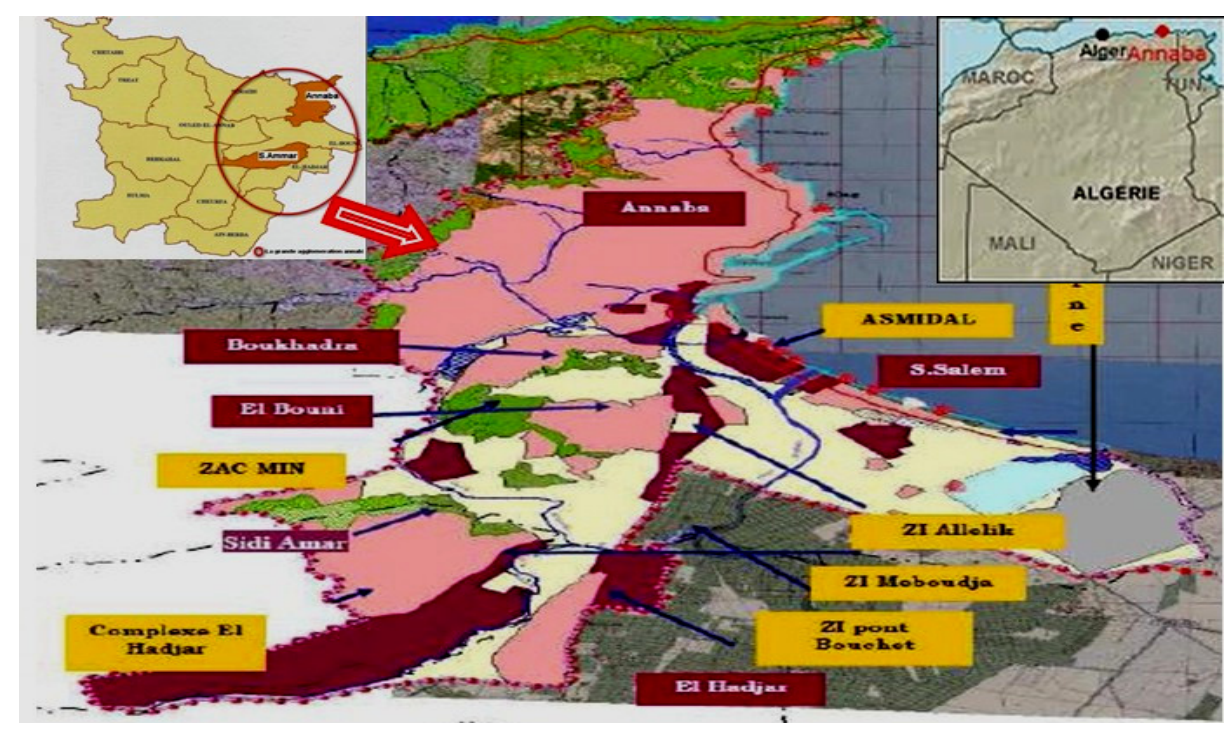

Figure 2. Geographical location of the Greater Annaba

This new formula has been beneficial, especially with the lack of reserve land on the one hand and the other hand to participate in improving the urban land scape with new aspects of modern architecture.

Projects that involved real estate development in the five-year program represent $11 \%$ of total housing part. Although, the rate of participation in solving the housing crisis is low, this formula reflects a quality of production by compared to other forms, through our air forceall programs of the study of real estate development were part of the commute Annaba, in coastal sites exposed to the rental period in the summer (see Figure 3).

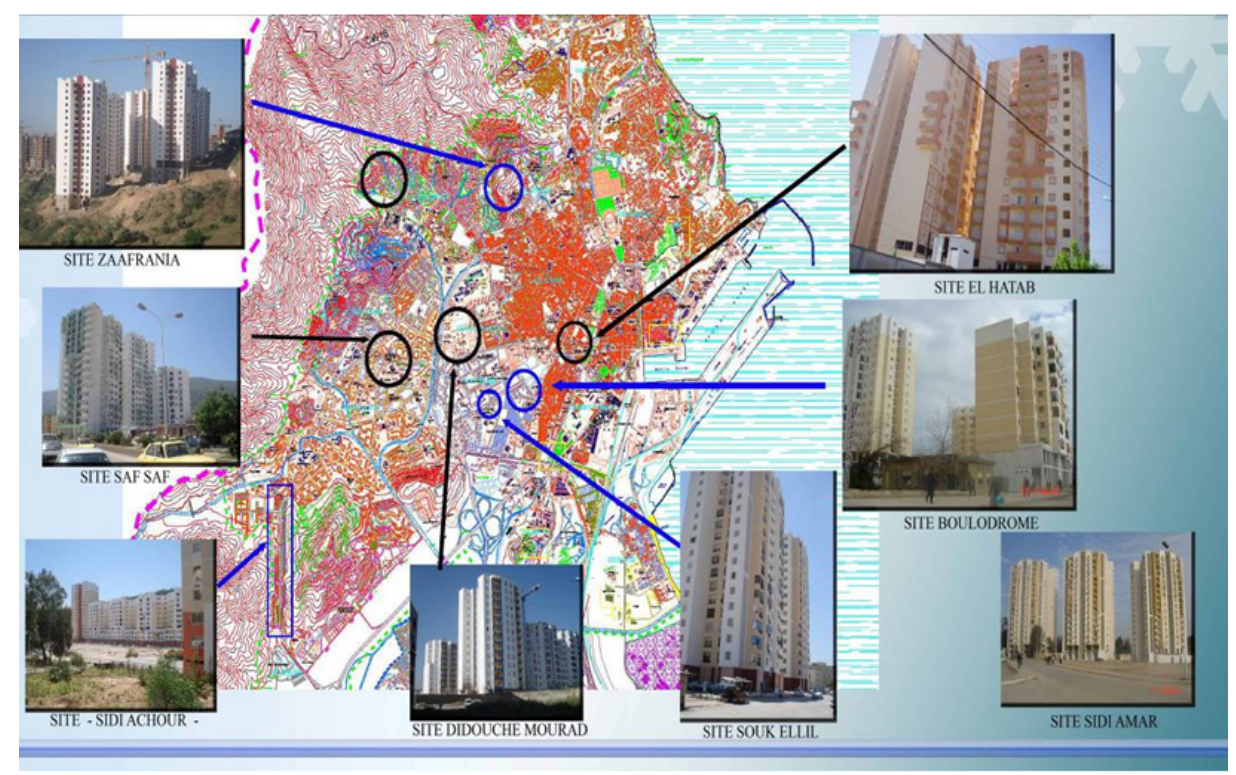

Figure 3. Location of accommodation sales (Rent -sale) in the Greater Annaba

The housing stock of Annabais balanced to carve out a promising prospect to absorb the housing crisis. Of a total of 50,000 units of all types, provided by the five-year program 2010/2014, during 2011, 17,670 housing units, including 11,170 social homes and 6,500 promotional helped (PCPA), were launched. The year 2012 will see the actual launch of 25,000 lodging with 10,000 (LPA), 400011000 LSL and promotional; during the same year, 10,189 units will be delivered and assigned. 


\section{Conclusion}

The vast shortage in housing, stability factor, requires immediate care of this problem and the implementation of a real emergency plan. It is essential, however, given the complexity of the problem, this issue must be understood in a general context of development and as a part of an overall strategy for housing and construction related:

- The policy of land

- The bold approach of demography

- The economic recovery

- The development of means of implementation

- The technological research in construction, building materials, architecture and education

- Fluency in land management

- The mobilization of financial resources: Cash, bank and Taxation

- The establishment of good coordination between different actors and stakeholders (local communities, master contractor, prime contractor and citizens) will produce an attractive housing stock and will meet the aspirations of the people according to their lifestyle and the vocation of space. The objective of the new housing strategy is to diversify the supply of housing by encouraging property development, and developing access to credit, but now using the state.

Housing is the main component of the urban fabric; each built up area should bewell serviced and managed. The informal areas and specially slums, when they exist, need greater attention in order to upgrade the prevailing living conditions.

Financial resources are becoming shorter and the housing needs greater. Toovercome this dilemma, it is possible to set ways for appropriate and affordable solutions. Soft and gradual actions are required to develop building capacities among concerned actors.

Different forms of housing opportunities could be made available through optimal use of the existing stock. The affordability aspect should be strengthened, mainly with regard to the low-income and vulnerable groups. Solidarity, communication and understanding are expectations in the housing field

Housing programs run under the five-year programs (2005-2009 and 2010-2014) in Annaba cityas well as in the Greater Annabi, decreasing the magnitude of the housing crisis and resolution squatter settlements. While the share of housing program promotional remained because of land constraints to characters and real estate development. The focus is on improving the urban landscape and quality of housing production.

It might be for our countries to make the transition from quantitative tothe qualitative aspect of housing, with globalization and qualitative improvement of the living population and enshrining the right to decent housing for all citizens applied elsewhere. It would be required to implement a strategy, a new approachwith methods and tools for effective action, including the participation of residents.

\section{References}

Avril, B., \& Roth, B. (1997). Property development. Paris: press bridge and roadways.

Bechade, A. (1997). Property development. Paris: PUF collection "I-Know-What".

Benamrane, D. (1980). Crisis lived.

Report CNES. (1995). Reporton social housing. Algiers: Commission population and social need.

Semmoud, B. (1998). Housing policy and access to housing in Algeria. Study collection of the directory of North Africa.

Sid Ahmed Soufiane. (2007). City and insecurity; any action for satellite city in the Greater Annabi. International seminar-city and health, University of Constantine.

Sid Ahmed Soufiane. (2010). The urban land-horizons and challenges. University of Batna.

Sid, B. (1986). Habitat in Algeria-player strategy and industrial logic. Edition OPU ALGIERS. 